\title{
A Salutogenic Approach to Physical Education in Schools
}

\author{
Daniel Klein ${ }^{1,2}$, Tobias Vogt ${ }^{3,4}$ \\ ${ }^{1}$ Institute of Sport Didactics and Physical Education, German Sport University, Cologne, Germany \\ ${ }^{2}$ Institute of Outdoor Sports and Environmental Science, German Sport University, Cologne, Germany \\ ${ }^{3}$ Institute of Professional Sport Education and Sport Qualifications, German Sport University, Cologne, Germany \\ ${ }^{4}$ Faculty of Sport Sciences, Waseda University, Shinjuku, Tokyo, Japan \\ Email: d.klein@dshs-koeln.de, t.vogt@dshs-koeln.de
}

How to cite this paper: Klein, D., \& Vogt, T. (2019). A Salutogenic Approach to Physical Education in Schools. Advances in Physical Education, 9, 188-196.

https://doi.org/10.4236/ape.2019.93013

Received: June 15, 2019

Accepted: August 5, 2019

Published: August 8, 2019

Copyright (c) 2019 by author(s) and Scientific Research Publishing Inc. This work is licensed under the Creative Commons Attribution International License (CC BY 4.0).

http://creativecommons.org/licenses/by/4.0/ (c) (†) Open Access

\begin{abstract}
Schools are an excellent setting for health promotion in children and adolescents. In particular the school subject physical education (PE) offers high potential in this regard. The following paper applies the salutogenic model of Aaron Antonovsky to PE in schools. This approach focuses on strengthening the sense of coherence with its central factors: comprehensibility, manageability and meaningfulness. A high sense of coherence mobilizes generalized resistance resources, results in positive coping strategies and contributes to well-being and health. The presented modified and adapted salutogenic model of health for PE may serve as one element of a schools' general concept for health promotion.
\end{abstract}

\section{Keywords}

Health Promotion, Salutogenesis, Children, School Setting, Well-Being, Sense of Coherence

\section{Introduction}

What makes people healthy? This question reflects a central issue of the salutogenic model developed by Aaron Antonovsky (Antonovsky, 1979; Antonovsky, 1987). Health promotion in children and adolescents is one important task of educational systems and schools, respectively.

First, the understanding of the term health has to be addressed. The French surgeon and philosopher René Leriche in 1936 defined health as "the silence of the organs" (cited after Bézy, 2009), meaning the absence of illness. This pathogenic viewpoint distinguishes between just two states: healthy or ill. In 1946, the 
World Health Organization (WHO) presented a more holistic definition, defining health as "a state of complete physical, mental and social well-being and not merely the absence of disease or infirmity". Moreover, "the enjoyment of the highest attainable standard of health is one of the fundamental rights of every human being without distinction of race, religion, political belief, economic or social condition" (WHO, 2014). This WHO-definition undisputedly constitutes a milestone and still is applicable today. Nevertheless, the definition may also raise a question: How realistic and achievable is complete physical, mental and social well-being for the individual human being in certain points and situations of life? Simply said: Can people with sore muscles not be and feel healthy? Can people going through social conflicts like a divorce not be and feel healthy? Can handicapped people not be and feel healthy?

Instead of a dichotomous state (healthy or ill) Antonovsky proposed a continuum model, which sees each individual, at a given point of time, somewhere along a health-ease/dis-ease continuum (Antonovsky, 1996). Salutary factors lead to a movement of people in the direction of the health end of the continuum. Therefore, this model implements a paradigm shift from pathogenesis to salutogenesis, searching for health-causing factors instead of health-threatening risk factors (Becker et al., 2010).

Physical activity is one example for a potentially health-causing factor. It was Plato (428/427-348/347 before Christ) already stating: "Lack of activity destroys the good condition of every human being, while movement and methodical physical exercise save it and preserve it" (date unknown; cited after Simons-Morton, 2009). Until today, numerous studies document positive health outcomes of physical activity and sports in children and youth, for example regarding cardiovascular health, fitness and motor development, mental health, self-concept and academic performance. Therefore, at least 60 minutes or more of enjoyable and developmentally appropriate moderate to vigorous physical activity are recommended for children and adolescents every day (Gao et al., 2018; Strong et al., 2005).

In this context, schools constitute an excellent setting for health promotion through compulsory curricular physical education (PE) and extra-curricular sport activities. The aim of the present paper is to apply the salutogenic model to PE in schools.

\section{Salutogenesis}

The idea of salutogenesis originated from studies including survivors of the holocaust. Antonovsky observed that, despite unimaginably horrifying experiences, some survivors recovered and even thrived. He concluded that actively health promoting salutary factors must exist. Therefore, he asked for the origins of health and how to create, enhance and improve physical, mental and social well-being for the individual human being (Antonovsky, 1987; Becker et al., 2010; Mittelmark \& Bauer, 2017). 
Central to the salutogenic model is the sense of coherence, defined as "a global orientation that expresses the extent to which one has a pervasive, enduring though dynamic feeling of confidence that one's internal and external environments are predictable and that there is a high probability that things will work out as well as can reasonably be expected" (Antonovsky, 1987). The sense of coherence shapes an individuals' attitude towards life as well as its handling of stressful situations and facilitates successful coping. It consists of three major factors (Antonovsky, 1996; Eriksson, 2017):

- Comprehensibility (cognitive): “The stimuli from one's internal and external environments in the course of living are structured, predictable, and explicable".

- Manageability (behavioural): "The resources are available to one to meet the demands posed by these stimuli".

- Meaningfulness (motivational and emotional): "These demands are challenges, worthy of investment and engagement".

Two actual reviews show that the sense of coherence constitutes a relevant personal resource, beginning to develop during childhood and playing a significant protective role at school-age. A high sense of coherence in children and adolescents is related to a better perceived health, social competence and academic motivation and to reduced stress, problems and medication usage (Braun-Lewensohn et al., 2017; Idan et al., 2017a). The strength of one's sense of coherence depends on the following life experiences: consistency, underload-overload balance and participation in socially valued decision-making (Antonovsky, 1996), all of which may excellently be fostered in a school setting. Children experience consistency if they feel secure and accepted; this forms the basis for the development of comprehensibility. Children experience self-efficacy if requirements are available to their developmental level and if their individual progress is accepted; this forms the basis for the development of manageability. Children experience resonance on their engagement, acceptance and respect of their strengths and weaknesses if they participate in social decision-making processes; this supports the development of meaningfulness (Krause, 2011).

Another important component of the salutogenic model are the so-called generalized resistance resources, comprising the following internal (e.g. genetic) and external (e.g. environmental) protective factors (Antonovsky, 1979; Antonovsky, 1987; Idan et al., 2017b): Material resources, knowledge and intelligence, ego identity, coping strategies, social support, commitment and cohesion, cultural stability, ritualistic activities, religion and philosophy, preventive health orientation, genetics and constitution, state of mind. The availability and mobilization of generalized resistance resources support positive coping strategies in situations of stress and tension.

In summary, life experiences shape the individuals' sense of coherence, which in turn mobilizes generalized resistance resources when faced with physical or psycho-social stressors, resulting in different possible coping strategies: Tension may be managed unsuccessfully (potentially leading to dis-ease) or with success 
(potentially leading to health-ease), in the latter case strengthening generalized resistance resources and shaping new positive life experiences. Schools represent a promising setting to apply a salutogenic approach for health promotion (Bauer, 2017; Jensen et al., 2017). Due to positive relations between physical activity and health, PE is a predestined school subject for this purpose (Qennerstedt, 2008).

Bronikowski and Bronikowska (2009) showed that a 15 months health related PE program led to an increased sense of coherence and cardiorespiratory fitness in adolescent boys through self-planned out-of-school activity. The authors conclude that PE in schools should include guided and supervised practice in the planning of own physical activities. In a cross-sectional study Bronikowski et al. (2017) examined associations between the sense of coherence and physical activity. Male adolescents with a higher sense of coherence had significantly higher levels of moderate to vigorous physical activity. A study of Mattila et al. (2011) revealed that a strong sense of coherence in 15-year-olds significantly is associated with lighter use of alcohol, being a non-smoker, better care of oral health and better social competence. Krause (2011) showed that the resources self-worth and sense of belonging constitute fundamental health factors in the early years of childhood and shape the sense of coherence. Successful health promotion therefore depends on an interaction of children, parents and teachers.

\section{Physical Education in German Schools}

PE in schools may pursue multiple aims (like personal development, fitness, inclusion, health or pleasure), always depending on country-specific cultural traditions and the underlying educational or didactical concepts. In Germany, most federal states refer to a concept of PE that is focused on a so-called two-fold mandate (MSW NRW, 2014):

- Supporting personal development through physical activity, play and sports (education through sport).

- Discovering physical activity, play and sports culture (education for sport).

Within this concept, central teaching principles are a multi-perspective view on physical activity, to initiate reflections on physical activity as well as to support understanding and participation. With regard to a multi-perspective view on physical activity, the following perspectives are explicitly named (MSW NRW, 2014):

- Improving perception skills, enhancing movement experiences.

- Expressing oneself physically, creating movements.

- Taking a risk, acting responsibly.

- Experiencing, understanding and assessing performance.

- Cooperating, competing and communicating.

- Promoting health and developing health awareness.

One or more of these perspectives may be applied to each activity conducted 
in PE lessons as well as in extra-curricular sport activities. In practice, the last-mentioned perspective gets applied less often than others, maybe because health is commonly not the main motivation for children and adolescents to be physically active. Nevertheless, the health perspective offers excellent starting points for a salutogenic approach. Students shall develop individual health-related competencies and learn how to be physically active in a health-promoting manner (MSW NRW, 2014). Health promotion in this sense may be understood as "the process of enabling people to increase control over, and to improve, their health" and health be seen as "a positive concept emphasizing social and personal resources, as well as physical capacities", like stated in the Ottawa Charter for Health Promotion (WHO, 1986). This implies to see health as a dynamic process without reducing it to not being diseased or overweight (Quennerstedt, 2008). Therefore, the focus should be on potentially positive effects of PE regarding the sense of coherence.

\section{A Salutogenic Approach to Physical Education}

Figure 1 displays a modified and adapted salutogenic model of health for PE in schools. The health-ease/dis-ease continuum described by Antonovsky (1979, 1987) is located at the bottom, the slider reflecting an individuals' well-being at a given point in time. The interrelations of life experiences, sense of coherence and generalized resistance resources are shown on the left, their possible influence on stressful situations causing tension and relevant coping strategies on the right

\section{Modified and adapted salutogenic model of health for physical education}

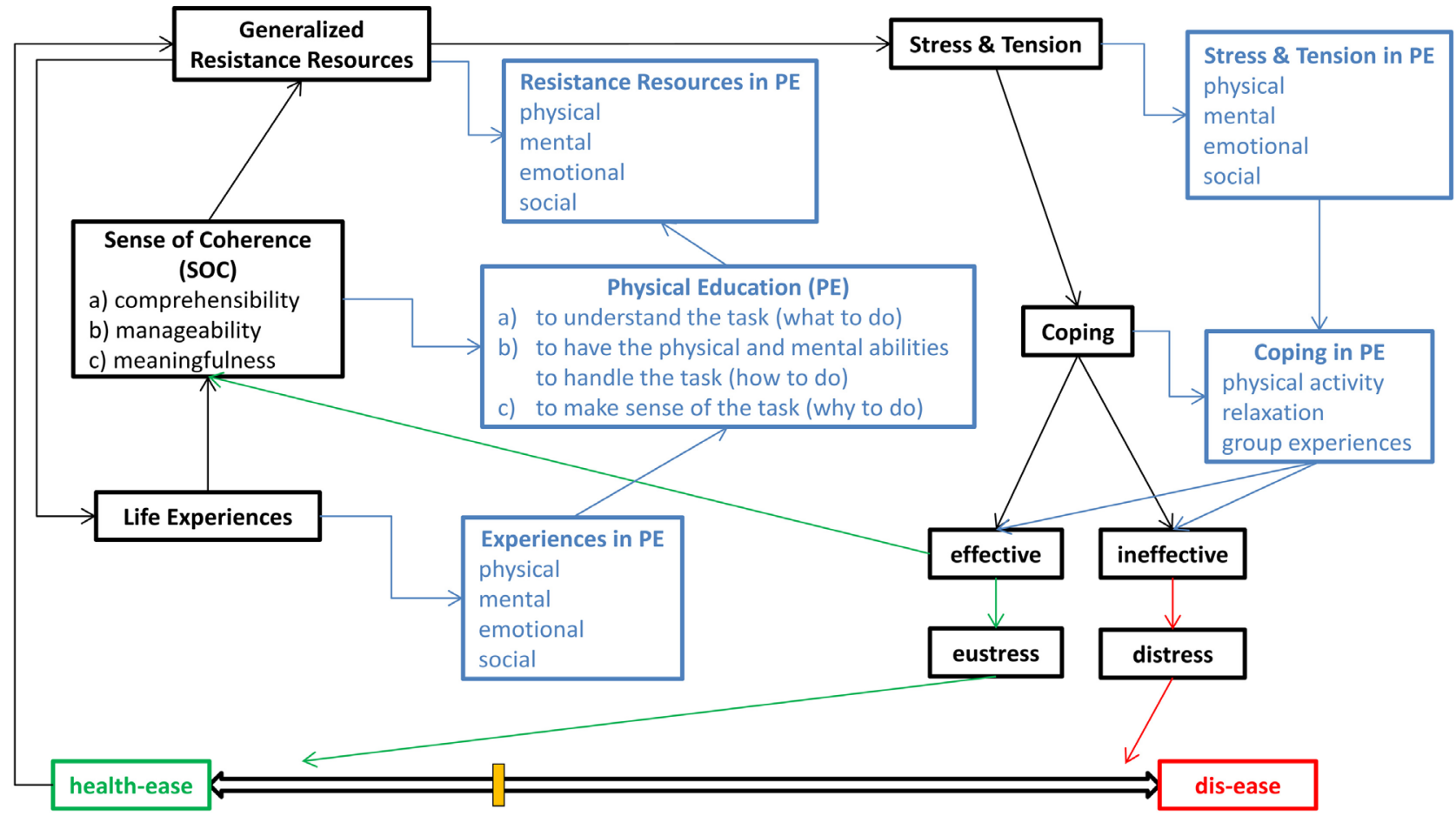

Figure 1. Modified and adapted salutogenic model of health for physical education. 
side of the model. For an individual it is beneficial to experience stress and tension, if coping strategies are effective, because this moves the slider to the health-ease end of the continuum and may strengthen the sense of coherence in the long term, if such experiences accumulate. Therefore, it is better to experience stress if you successfully cope, than not to experience any stress at all.

When transferring the salutogenic approach to PE in schools, the sense of coherence remains the heart of the model. Therefore, teachers have to consider its three core components in planning and conducting their PE lessons: comprehensibility, manageability and meaningfulness. Students have to:

1) Understand the task ("What to do?").

2) Have the physical and mental abilities to handle the task ("How to do?").

3) Make sense of the task (“Why to do?").

1) Teachers have to explain tasks and rules in an age-appropriate way that every single student understands with his or her individual cognitive abilities. Visualization may assist verbalization and movement tasks should always be demonstrated. Students should take over responsibilities (e.g. providing assistance, arranging equipment) in order to foster their understanding and participation.

2) Teachers have to vary, differentiate and individualize tasks in a way that every student can handle them with his or her individual physical and mental abilities. In heterogeneous or inclusive classes different learning goals may be appropriate for different students.

3) The before-mentioned points should be basics of every PE lesson. The most important mission for teachers is that their students are able and willing to make sense of a task. Of course this depends on the individual motivation to participate in physical activities. Nevertheless, the teacher should always be able to explain why he or she assigns a task, but at the same time be aware that every student may conclude a different sense of each task for oneself. In this regard, the teaching principle of reflection is absolutely crucial and should be an essential part of every PE lesson. The three questions "What to do?", "How to do?" and "Why to do?" may be employed after having made physical, mental, emotional and/or social experiences. The individual answers do not have to be congruent and may differ between students, especially regarding the "Why to do?"; this could be subject of further reflection.

In the described way, accumulated positive experiences in sports and PE may enhance aspects of the sense of coherence and built up resistance resources. These can be physical (e.g. fitness), mental (e.g. self-concept, resilience), emotional (e.g. impulse control) or social (e.g. feeling of belonging) and positively influence future experiences. Therefore, PE should create situations of (positive) stress and tension: For example, physical tension may originate from exhausting movement, mental tension be created when searching for an optimal tactic, emotional tension when a game is at the tipping point, and social tension when students have to cooperate to solve a movement task. Important are relevant 
coping strategies such as consciously experiencing the change between physical tension and relaxation or being a fair winner (not degrading your opponent) or loser (congratulating your opponent). Through effective coping strategies the slider on the continuum of well-being might move a little bit in the direction of health-ease.

At this point, once again Antonovsky (1996) shall be cited, because surely PE can just be a tessera and like other activities "will not radically transform anyone's sense of coherence. What they can do is prevent damage, perhaps add a little strength and, in some cases, create an opening for the beginning of a major change in life circumstances". The application of the presented model in PE may contribute to this issue.

\section{Conclusion}

The salutogenic model (Antonovsky, 1979; Antonovsky, 1987) provides an excellent approach for health promotion through PE in schools. Teachers should aim at strengthening the health-orientated resources of their students instead of focusing on deficit-orientated risk-factors as well as empower and motivate them to live their life healthy and physically active. Thereby, different and wider perspectives of health should be highlighted and reflected, not only focusing on physical fitness, but also mental, emotional and social aspects of health, always asking "What keeps us healthy?" in these domains or, more general, "How can I live a good life?” (McCuaig \& Quennerstedt, 2018; Quennerstedt, 2008). Learning, empowerment, quality of life, resilience, well-being, coping or self-efficacy may be some issues to address. By focusing on individual resources and strengths, the salutogenic model may especially be applicable for inclusive health promoting PE, including children with special needs. A salutogenic orientation holistically relates to all aspects of a person and illuminates salutary factors instead of particular pathology or disability (Mittelmark \& Bauer, 2017). Therefore, a salutogenic approach should explicitly be included in curricula for PE in schools, when aiming at health promotion. It should be subject to future studies, if the sense of coherence as a global life orientation in fact may be positively influenced by PE. Appropriate instruments for measuring the sense of coherence are available (Antonovsky, 1987; Idan et al., 2017a; Mattila et al., 2011).

The application of salutogenesis in schools has been described before as a general concept for health promoting schools (Jensen et al., 2017), but rarely with a focus on the school subject PE (Quennerstedt, 2008). The presented modified and adapted salutogenic model of health for PE may serve as one element of a schools' general concept for health promotion and build a basis for further considerations.

\section{Conflicts of Interest}

The authors declare no conflicts of interest regarding the publication of this paper. 


\section{References}

Antonovsky, A. (1979). Health, Stress and Coping. San Francisco, CA: Jossey-Bass.

Antonovsky, A. (1987). Unraveling the Mystery of Health. San Francisco, CA: Jossey-Bass.

Antonovsky, A. (1996). The Salutogenic Model as a Theory to Guide Health Promotion. Health Promotion International, 11, 11-18. https://doi.org/10.1093/heapro/11.1.11

Bauer, G. F. (2017). The Application of Salutogenesis in Everyday Settings. In M. B. Mittelmark, S. Sagy, M. Eriksson, G. F. Bauer, J. M. Pelikan, B. Lindström, \& G. A. Espnes (Eds.), The Handbook of Salutogenesis (pp. 153-158). Basel: Springer. https://doi.org/10.1007/978-3-319-04600-6 16

Becker, C. M., Glascoff, M. A., \& Felts, W. M. (2010). Salutogenesis 30 Years Later: Where Do We Go from Here? International Electronic Journal of Health Education, 13, 25-32.

Bézy, O. (2009). La santé c'est la vie dans le silence des organs (Health Is Life Lived in the Silence of the Organs). La revue lacanienne, 3, 47-50.

Braun-Lewensohn, O., Idan, O., Lindström, B., \& Margalit, M. (2017). Salutogenesis: Sense of Coherence in Adolescence. In M. B. Mittelmark, S. Sagy, M. Eriksson, G. F. Bauer, J. M. Pelikan, B. Lindström, \& G. A. Espnes (Eds.), The Handbook of Salutogenesis (pp. 123-136). Basel: Springer. https://doi.org/10.1007/978-3-319-04600-6 14

Bronikowski, M., \& Bronikowska, M. (2009). Salutogenesis as a Framework for Health Resources in Adolescent Boys. Scandinavian Journal of Public Health, 37, 525-531. https://doi.org/10.1177/1403494809105289

Bronikowski, M., Laudanska-Krzeminska, I., Tomczak, M., \& Morina, B. (2017). Sense of Coherence, Physical Activity and Its Associations with Gender and Age among Kosovar Adolescents: A Cross-Sectional Study. The Journal of Sports Medicine and Physical Fitness, 57, 1023-1032.

Eriksson, M. (2017). The Sense of Coherence in the Salutogenic Model of Health. In M. B. Mittelmark, S. Sagy, M. Eriksson, G. F. Bauer, J. M. Pelikan, B. Lindström, \& G. A. Espnes (Eds.), The Handbook of Salutogenesis (pp. 91-96). Basel: Springer.

Gao, Z., Chen, S., Sun, H., Wen, X., \& Xiang, P. (2018). Physical Activity in Children's Health and Cognition. BioMed Research International, 2018, Article ID: 8542403. https://doi.org/10.1155/2018/8542403

Idan, O., Braun-Lewensohn, O., Lindström, B., \& Margalit, M. (2017a). Salutogenesis: Sense of Coherence in Childhood and in Families. In M. B. Mittelmark, S. Sagy, M. Eriksson, G. F. Bauer, J. M. Pelikan, B. Lindström, \& G. A. Espnes (Eds.), The Handbook of Salutogenesis (pp. 107-121). Basel: Springer.

https://doi.org/10.1007/978-3-319-04600-6 13

Idan, O., Eriksson, M., \& Al-Yagon, M. (2017b). The Salutogenic Model: The Role of Generalized Resistance Resources. In M. B. Mittelmark, S. Sagy, M. Eriksson, G. F. Bauer, J. M. Pelikan, B. Lindström, \& G. A. Espnes (Eds.), The Handbook of Salutogenesis (pp. 57-69). Basel: Springer. https://doi.org/10.1007/978-3-319-04600-6 7

Jensen, B. B., Dür, W., \& Buijs, G. (2017). The Application of Salutogenesis in Schools. In M. B. Mittelmark, S. Sagy, M. Eriksson, G. F. Bauer, J. M. Pelikan, B. Lindström, \& G. A. Espnes (Eds.), The Handbook of Salutogenesis (pp. 225-235). Basel: Springer.

Krause, C. (2011). Developing Sense of Coherence in Educational Contexts: Making Progress in Promoting Mental Health in Children. International Review of Psychiatry, 23, 525-532. https://doi.org/10.3109/09540261.2011.637907

Mattila, M. L., Rautava, P., Honkinen, P. L., Ojahlatva, A., Jaakkola, S., Aromaa, M., Suominen, S., Helenius, H., \& Sillanpäa, M. (2011). Sense of Coherence and Health Beha- 
vior in Adolescence. Acta Paediatrica, 100, 1590-1595.

https://doi.org/10.1111/j.1651-2227.2011.02376.x

McCuaig, L.,\& Quennerstedt, M. (2018). Health by Stealth-Exploring the Sociocultural Dimensions of Salutogenesis for Sport, Health and Physical Education Research. Sport, Education and Society, 23, 111-122. https://doi.org/10.1080/13573322.2016.1151779

Mittelmark, M. B., \& Bauer, G. F. (2017). The Meanings of Salutogenesis. In M. B. Mittelmark, S. Sagy, M. Eriksson, G. F. Bauer, J. M. Pelikan, B. Lindström, \& G. A. Espnes (Eds.), The Handbook of Salutogenesis (pp. 7-13). Basel: Springer. https://doi.org/10.1007/978-3-319-04600-6

MSW NRW (Ministry of School and Continuing Education, North-Rhine Westphalia) (2014). Rahmenvorgaben für den Schulsport in Nordrhein-Westfalen (Framework Specifications for Physical Education in North-Rhine Westphalia). Düsseldorf: MSW NRW.

Quennerstedt, M. (2008). Exploring the Relation between Physical Activity and Health-A Salutogenic Approach to Physical Education. Sport, Education and Society, 13, 267-283. https://doi.org/10.1080/13573320802200594

Simons-Morton, D. G. (2009). ACSM's Exercise Is Medicine ${ }^{\mathrm{m}}$ : A Clinician's Guide to Exercise Prescription. American Journal of Preventive Medicine, 37, 576.

https://doi.org/10.1016/j.amepre.2009.08.021

Strong, W. B., Malina, R. M., Blimkie, C. J. R., Daniels, S. R., Dishman, R. K., Gutin, B., Hergenroeder, A. C., Must, A., Nixon, P. A., Pivarnik, J. M., Rowland, T., Trost, S., \& Trudeau, F. (2005). Evidence Based Physical Activity for School-Age Youth. The Journal of Pediatrics, 146, 732-737. https://doi.org/10.1016/j.jpeds.2005.01.055

World Health Organization (1986). The Ottawa Charter for Health Promotion. Https:/www.who.int/healthpromotion/conferences/previous/ottawa/en/

World Health Organization (2014). Constitution of the World Health Organization. In Basic Documents (pp. 1-19). Geneva: WHO Press. 